\title{
Architecture to Integrate Broadband Access Networks and Wireless Grids
}

\author{
João Paulo Ribeiro Pereira \\ Instituto Politécnico de Bragança (IPB) \\ Bragança, Portugal \\ jprp@ipb.pt
}

\begin{abstract}
Today, the access networks face two main challenges: the increasing bandwidth demand and mobility trends. All this will require fundamental changes to the operations of access networks, the functionality of network nodes and the architecture itself. By other side, the evolution of computing and communication networks toward decentralized and distributed systems implies that all the intelligence is on the edge nodes of the networks. Integrating wireless devices with the traditional wired grid infrastructure will allow the access (transfer, processing, etc) to the information that is now scattered across the different devices. In this paper, we present a new architecture and a cost model to support the new requirements of broadband access (fixed and nomadic users) and wireless grids in an integrated way
\end{abstract}

Keywords: Wireless Grids, Access Networks, Broadband Access Technologies, Techno-economic Cost Model.

\section{Introduction}

Actually, the development of wireless technology and mobile devices enable us to access the network services from anywhere at any time [1]. The wireless devices (mobile phones, PDAs, laptops, sensors, etc) have an important role in our daily. Computing and communication networks have evolved from centralized, hierarchical systems under the management of a single entity toward decentralized, distributed systems under the collective management of many entities. Today, all the intelligence is in the edge nodes of the networks, which implies that information is now scattered across the different devices [2] [3].

By other side, the increasing demand of "quad-play" (also known as quadrupleplay) services, including video, voice, data and mobility, have created new challenges to the modern broadband wireless/wired access networks [4]. Actually, the access networks face two main challenges: the increasing bandwidth demand and mobility trends. All this will require fundamental changes to the operations of access networks, the functionality of network nodes, and the architecture itself.

In this context, we propose a techno-economic model to support the new requirements of broadband access (fixed and nomadic users) and wireless grids in an integrated way (Figure 1). The approach has two main objectives: a) Provide broadband access to end users, and b) Support the implementation of wireless grids (our

T. Doulamis et al.: (Eds.): GridNets 2009, LNICST 25, pp. 119-130, 2010.

(C) Institute for Computer Sciences, Social-Informatics and Telecommunications Engineering 2010 
architecture assumes that the wireless grids must have some access to the access network infrastructure).The final result is an integrated architecture that includes the 2 main components: Broadband access and wireless grids.

\section{Framework}

\subsection{Broadband Access Networks}

The requirements for bandwidth capacity have increased significantly over the last several years [5]. The requirements for services such as HDTV, video conferences, peer-to-peer traffic, etc., have led to predictions of bandwidth consumption of at least $50 \mathrm{Mbps}$ downstream for residential consumers and in the region of 8 Mbps upstream [6]. The "triple play" services (Internet, telephone and TV services), lead to a great increase in bandwidth demand. However, the existing access networks are not able to support this increase and the capacity to deliver broadband services remains a challenge ("last mile problem"). The access network remains a bottleneck in terms of the bandwidth and service quality it affords the end user.

Besides the bandwidth, other great challenge to access networks is the mobility and the user needs to have internet access anywhere and anytime. The mobility of the enduser will also introduce an unprecedented volatility to the network architecture [7;8]. Nomadicity causes end-users to pop up and disappear at different locations in the network.

\subsection{Wireless Grids}

Wireless Grid (WG) is an emerging communication and resource sharing architecture that has been discussed in recent years. The WG expand the scope of resources to include peripherals: display, camera, microphone, etc. Wireless peripherals and the access device form an ad hoc network and communicate with each other and allow the ad hoc sharing of resources (e.g., microphones, screens, processing power) of edge devices (e.g., mobile phone, laptop, PDA) [9]. In a wireless grid, the edge nodes are the network.

A large number of these devices arrive and depart frequently on wireless grids. Then, as wireless devices have different spatial behavior, they are divided into 3 main categories: Mobile, nomadic and fixed-location wireless devices. Wireless grid solutions offer to home broadband users, the maximum ability to share necessary documents, DVDs, music, displays, cameras, printers, sensors and so on [10].

\subsection{Cost Model Framework}

The proposed model considers two main parts (see figure 1): Broadband Access and Wireless Grids. Broadband access part analyses two perspectives: static layer and nomadic layer. The proposed model considers that in the static layer, users are stationary and normally require data, voice, and video quality services (these subscribers demand great bandwidth). In the nomadic layer (or mobility layer), the main concern is mobility and normally the required bandwidth is smaller than in the static layer. The focus of the wireless networks was to support mobility and flexibility, while for 
the wired access networks is bandwidth and high QoS [4]. To support the static layer we consider five technologies: FTTH(PON), DSL, HFC, PLC, and WiMAX. For the nomadic layer we chose the WiMAX solution.

To support the Wireless Grids part we consider several technologies: Wi-Fi, Bluetooth, UWB, ZigBee, 3G, etc. As we can see in figure 1, our model divides the area into several access networks, and we can have different solutions for each one.

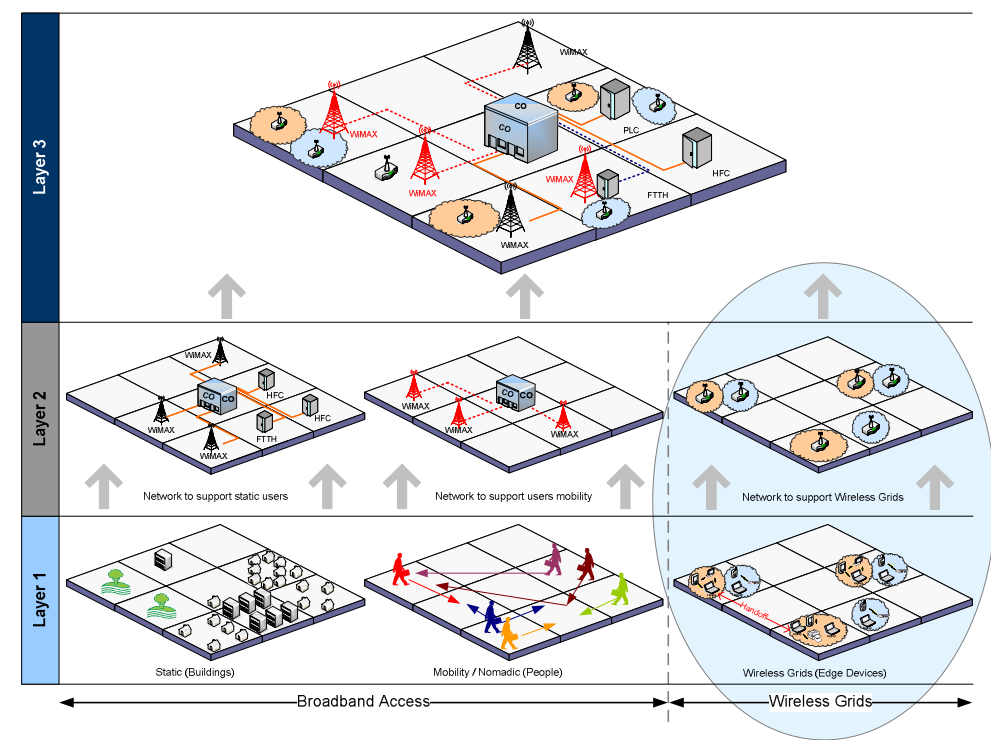

Fig. 1. Cost model framework

Methodology used for Broadband Access: As we can see in Figure 1, the framework is divided into three main layers:

- (Layer 1) First, we identify for each sub-area the total households and SMEs (Static analysis), and total nomadic users (Mobility analysis). The proposed model initially separates these two components because they have different characteristics.

- (Layer 2) In this layer, the best solution for each access network is analyzed (static and nomadic perspective). For the static analysis we consider Fiber to the Home (FTTH- PON), Digital Subscriber Line (DSL), Hybrid Fiber Coax (HFC), Power Line Communications (PLC) and WiMAX technologies, and for the nomadic analysis we use the WiMAX technology. Then, the final result of this layer is the best technological solution to support the different needs (Static and nomadic). The selection of the best option is based in four output results: NPV, IRR, Cost per subscriber in year 1, and Cost per subscriber in year $\mathrm{n}$.

- (Layer 3) The next step is the construction of a single infrastructure that supports the two components. To this end, the tool analyses for each access network which is the best solution (based on NPV, IRR, etc). Finally, for each 
sub-area we verify if the best solution is: a) The wired technologies (FTTH, DSL, HFC, and PLC) to support the static component and the WiMAX technology for mobility; or b) The use of WiMAX technology to support the fixed and nomadic component.

Methodology used for Wireless Grids: (Layer 1) First, we identify for each sub-area the total HH (residential) and SMEs (school, hospital, etc.) with wireless grids. (Layer 2) In this layer, the model identifies the necessary components to support the wireless grids. Finally, in layer 3 we propose an integrated architecture.

\section{Cost Model}

The model focuses the access part of the network (that starts at $\mathrm{CO}$ and end at the subscriber CPE) and the wireless grids.

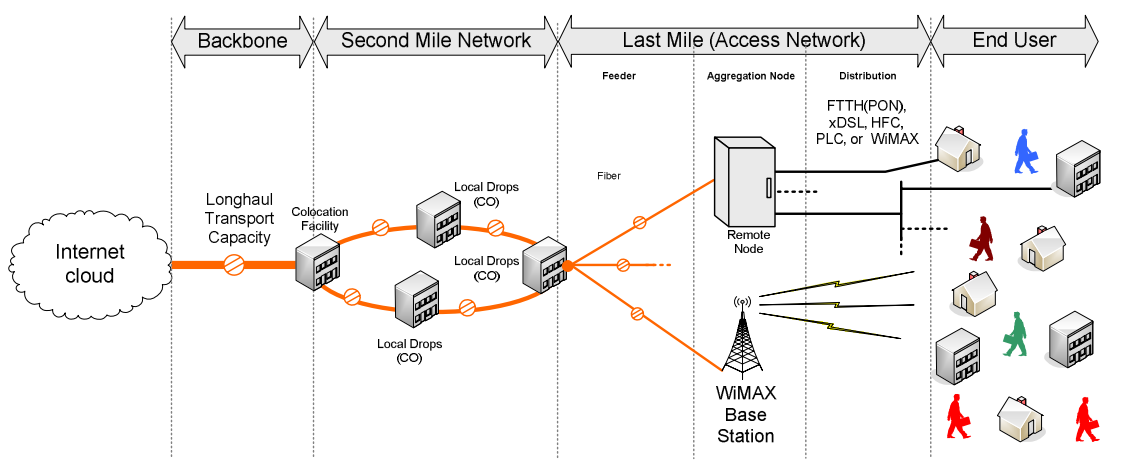

Fig. 2. General System Architecture

\subsection{Access Network Architecture}

To provide BB access, our model considers five technologies: FTTH(PON), HFC, $\mathrm{xDSL}, \mathrm{PLC}$, and WiMAX. The outside segment is divided into three main parts (see Figure 3) [5]: Feeder, Aggregation Nodes and Distribution (for HFC technology the distribution segment is divided into distribution and drop).

Feeder segment is the network between the $\mathrm{CO}$ and the aggregation nodes. The model includes not only the cost of equipment (Fiber repeaters), but also the optical fiber cables, installation, trenches, and housing (street cabinets) costs. The ducts can be shared by several optical fiber cables.

The aggregation nodes are located in access areas street cabinets. The components of these nodes depend on the technology. In the next paragraphs we will present the elements for the five technologies in study.

The distribution network links the aggregation nodes with CPE. Like feeder networks, in distribution, the model includes not only the cost of equipment (copper, coax, and LV grid repeaters), but also the cables, installation and trenches costs. 


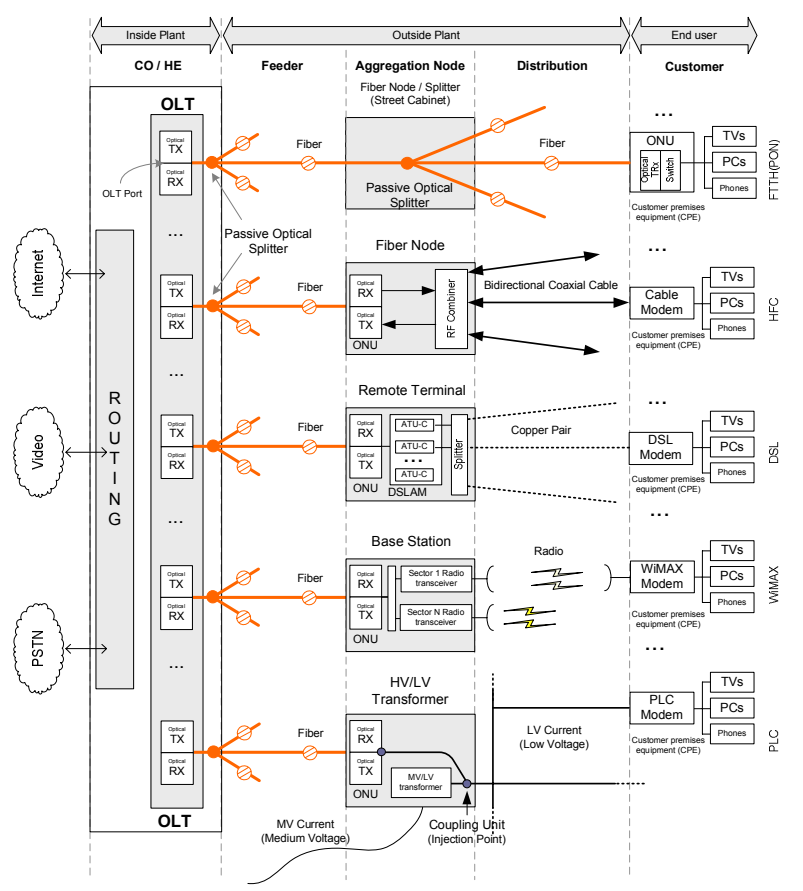

Fig. 3. Block Diagram for Access Technologies [4]

\subsection{Wireless Grid Architecture}

Wireless grid architecture is mainly consisted of backbone networks and wireless ad hoc sub networks, partially similar to P2P network [11]. To [3], wireless grids are limited by the device resources, and there is a typical architecture that a backbone grid comprised of wired and fixed grid devices, several access grid comprised of wireless devices which can access the processing, storage, bandwidth of backbone grid. Access grid connects to backbone grid by wireless mode, such as Ultra Wideband (UWB), ZigBee, WLAN, Cellular network (2G/2.5G/3G/B3G/4G), etc (see table 1).

Table 1. Wireless Technologies (WLAN and WPAN)

\begin{tabular}{|c|c|c|c|c|c|}
\hline & Wi-Fi & UWB & Bluetooth & ZigBee & $3.5 \mathrm{G}$ \\
\hline Standard & $802.11 \mathrm{~g}$ & $802.15 .3 \mathrm{a}$ & 802.15 .1 & 802.15 .4 & UTRA FDD R5 \\
\hline Usage & WLAN & WPAN & WPAN & WPAN & $3.5 \mathrm{G}$ \\
\hline Throughput & $\begin{array}{l}54 \mathrm{Mbps}(20 \mathrm{~m}) \\
6 \mathrm{Mbps}(60 \mathrm{~m})\end{array}$ & 55-480 Mbps & 2-3 Mbps & $250 \mathrm{Kbps}$ & 1.8 to $14.4 \mathrm{Mbps}$ \\
\hline Range & $100 \mathrm{~m}$ & $<10 \mathrm{~m}$ & $10 \mathrm{~m}$ & $50 \mathrm{~m}$ & $5000 \mathrm{~m}$ \\
\hline Frequency & $2.4 \mathrm{GHz}$ & $\begin{array}{c}3.1-10.6 \\
\mathrm{GHz}\end{array}$ & $2.4 \mathrm{GHz}$ & $2.4 \mathrm{GHz}$ & $\begin{array}{l}\text { Tx: } 1920-1980 \mathrm{MHz} \\
\text { Rx: } 2110-2170 \mathrm{MHz}\end{array}$ \\
\hline
\end{tabular}


In the proposed architecture (see Figure 4), edge devices are connected via adhoc wireless networks, and the devices may come and go (i.e. spatial behavior). The architecture assumes that the wireless grids must have some access to the access network infrastructure. The architecture uses an edge interface (Edge router) to connect the wireless grids to the broadband infrastructure (Access Network). Then, the wireless grid solutions offer to broadband users the maximum ability to share documents, music, cameras, displays, printers, sensors and so on.

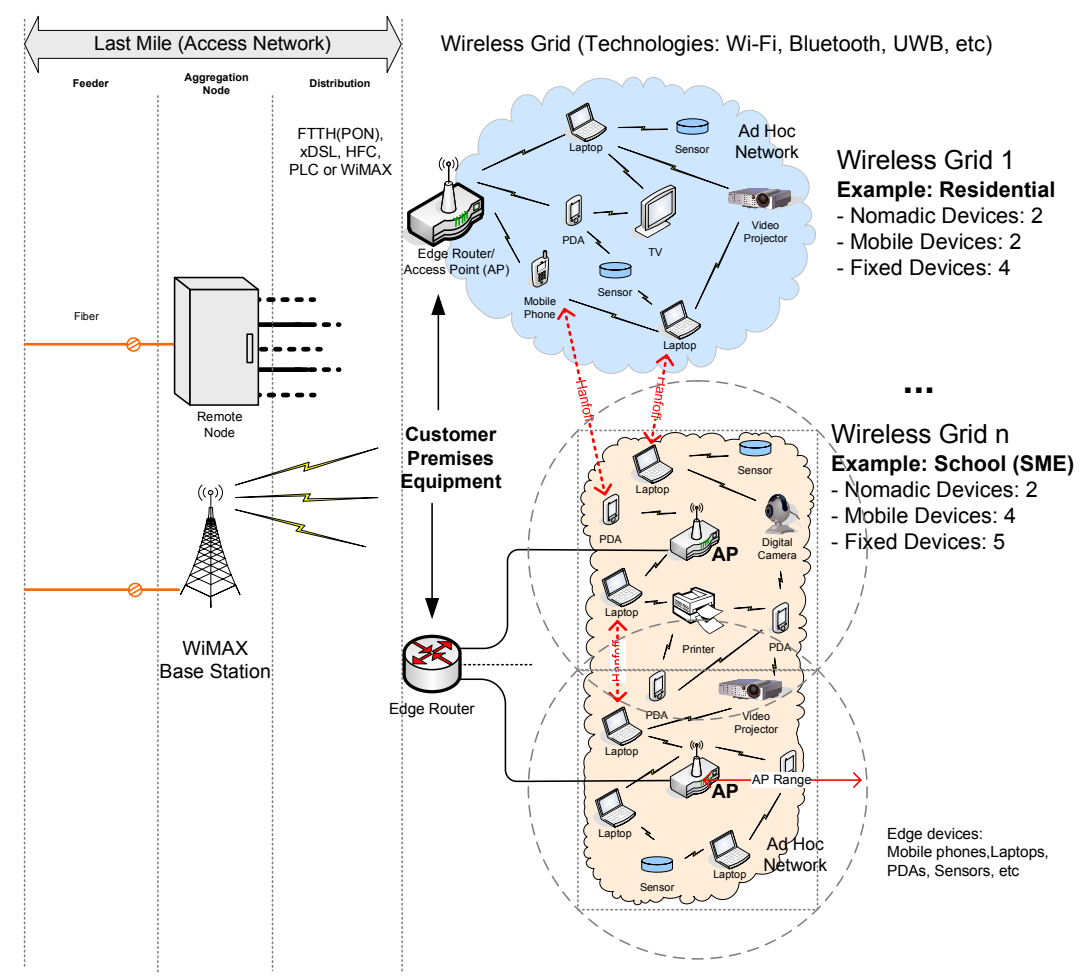

Fig. 4. Architecture for Wireless Grids

As referred above, in our model we consider that the edge devices are divided into 3 types: Nomadic, mobile and fixed. The wireless grid connects to backbone by wireless mode (Wi-Fi technology). The wireless links between the edge devices in the wireless grids can be supported by several wireless technologies (see Table 1): Wi-Fi, Bluetooth, UWB, ZigBee, 3G, etc. Then, in each wireless grid, the devices can use the Wi-Fi links (in our model, the Wi-Fi signal is propagated in all area of the wireless grid), or other technology (Bluetooth, UWB, etc) if the device don't has the Wi-Fi technology. 

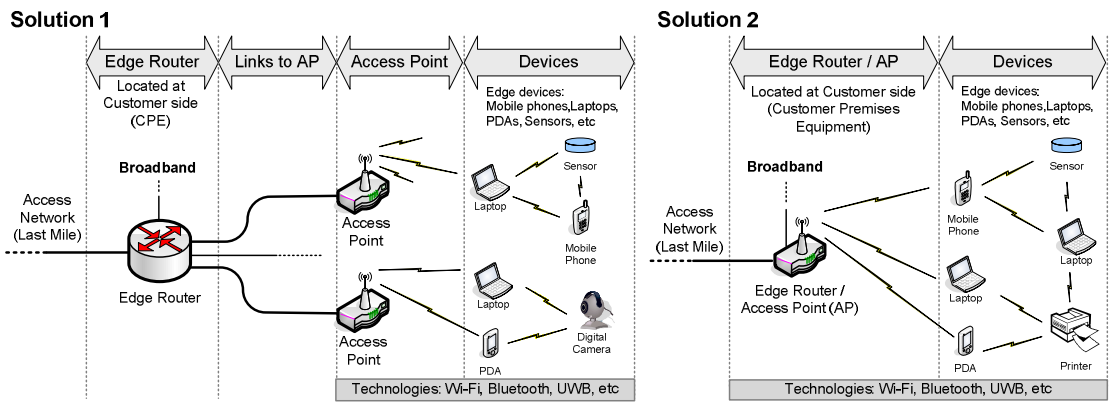

Fig. 5. Block diagram of Wireless Grids systems architecture

As we can see in figure 5, our model divides the wireless grid system architecture into two or four main segments (depend on the solution): edge router, link to access point equipment, access point equipment, and devices. The components used to compute the results for wireless grids are presented in the next table. The costs of devices are supported by the costumers.

Table 2. Wireless Grids architecture components

\begin{tabular}{lllll}
\hline Edge Router & Links to APs & Wireless Access Points & Devices \\
\hline 1) Router equipment; & 1) Cable; & 1) AP equipment; & $\begin{array}{l}\text { Cost supported by the } \\
\text { customer. }\end{array}$ \\
& $\begin{array}{l}\text { 2) Cable } \\
\text { installation }\end{array}$ & 2) Equipment installation & $\begin{array}{l}\text { 1) Equipment: Nomadic, } \\
\text { Mobile, and Fixed devices }\end{array}$ \\
\hline
\end{tabular}

Geometric Model Assumptions. The geometrical model definition is required to calculate the length of cables (from edge router to wireless gateways) and the total cells required to cover all the wireless grid area (see figure 6).

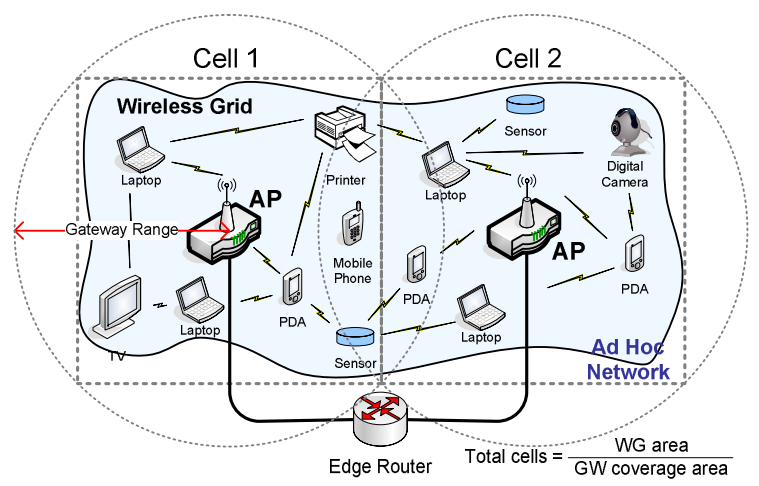

Fig. 6. Geometric model for Wireless Grids 


\section{Results}

\subsection{Scenario Description}

\subsubsection{Scenario Description for Access Network}

The three main activities for scenario description are: area definition, definition of the set of services to be offered, and the pricing (see Table 3). Table 3 shows the general input parameters used in our model and tool. The trends for each parameter are presented in the last column. This scenario is defined for a study period of 15 years and for an urban area. The definition of the area type is essential because several costs between urban and rural areas are different.

Table 3. General Input Parameters for Access Network

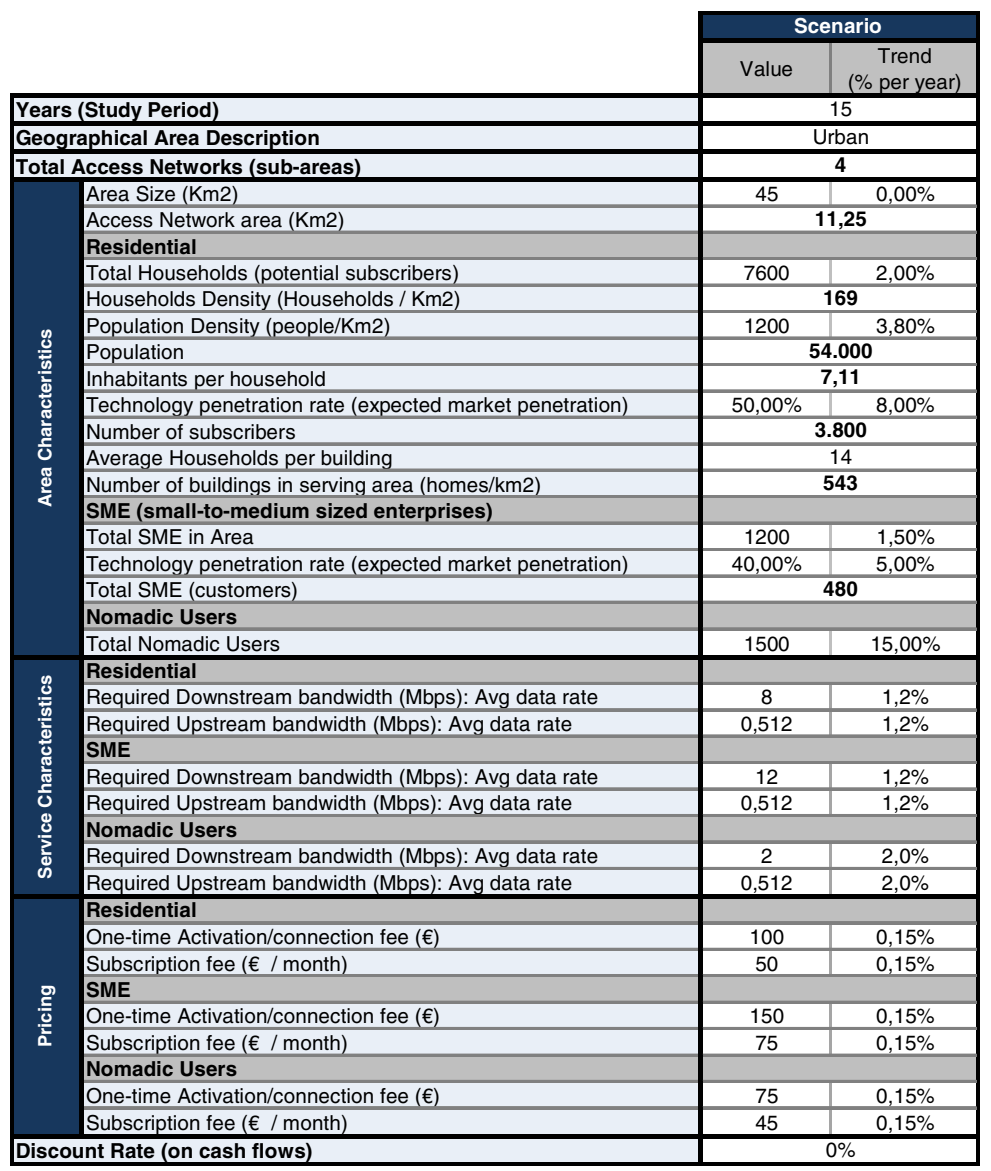


After the general specification, is obligatory the definition of the number of access networks in which we want to divide the area in study is compulsory (between 1 and 36). This scenario assumes the division into 4 sub-areas (or access networks). Following, the definition of the number of households (HH), SMEs and nomadic users is also required, for each access network (see Table 4).

Table 4. Input Parameters for each Access Network

\begin{tabular}{r|c|c|c|c|c|} 
& $\begin{array}{c}\text { Access } \\
\text { Network 1 }\end{array}$ & $\begin{array}{c}\text { Access } \\
\text { Network 2 }\end{array}$ & $\begin{array}{c}\text { Access } \\
\text { Network 3 }\end{array}$ & $\begin{array}{c}\text { Access } \\
\text { Network 4 }\end{array}$ & $\begin{array}{c}\text { Total Area } \\
\text { (Year1) }\end{array}$ \\
\hline Total HH: & 6000 & 0 & 500 & 1100 & $\mathbf{7 6 0 0}$ \\
\hline Total SME: & 1000 & 0 & 150 & 50 & $\mathbf{1 2 0 0}$ \\
\hline Total Nomadic Users: & 500 & 0 & 1000 & 0 & $\mathbf{1 5 0 0}$ \\
\hline
\end{tabular}

\subsubsection{Scenario Description for Wireless Grids}

The chosen scenario consists of 2770 residential wireless grids and 555 SMEs with wireless grids (Year 1), uniformly distributed in square area of $45 \mathrm{~km} 2$ (table 5). Each mobile and nomadic device selects a random destination within the area (in a specific wireless grid, for mobile devices, and between wireless grids for nomadic devices).

Table 5. Wireless Grids Parameters definition

\begin{tabular}{|c|c|c|c|c|c|c|c|}
\hline & & & $\begin{array}{l}\text { Access } \\
\text { Network } 1\end{array}$ & $\begin{array}{c}\text { Access } \\
\text { Network } 2\end{array}$ & $\begin{array}{l}\text { Access } \\
\text { Network } 3\end{array}$ & $\begin{array}{c}\text { Access } \\
\text { Network } 4\end{array}$ & $\begin{array}{c}\text { Total Area } \\
\text { (Year 1) }\end{array}$ \\
\hline & & Total HH(Year 1): & 6000 & 0 & 500 & 1100 & 7600 \\
\hline & & Total SMEs (Year 1): & 1000 & 0 & 150 & 50 & 1200 \\
\hline \multirow{5}{*}{ 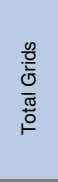 } & \multicolumn{6}{|c|}{$\begin{array}{c}\text { Trend } \\
\text { (\%per year) }\end{array}$} & \\
\hline & \%HH with WG (Residential) & $1,50 \%$ & $40,00 \%$ & $0,00 \%$ & $30,00 \%$ & $20,00 \%$ & \\
\hline & Total HH with WG(Year 1) & & 2400 & 0 & 150 & 220 & 2770 \\
\hline & \%SMEwith WG (School, Hospital, etc) & $2,00 \%$ & $45,00 \%$ & $0,00 \%$ & $50,00 \%$ & $60,00 \%$ & \\
\hline & Total SMEwith WG(Year 1) & & 450 & 0 & 75 & 30 & 555 \\
\hline \multirow{10}{*}{ 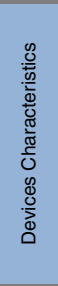 } & \multicolumn{6}{|l|}{ Devices per WG: HH (Residential) } & \\
\hline & AVGnumber of Mobile devices per WG & $0,25 \%$ & 4 & 0 & 2 & 5 & 11 \\
\hline & AVG number of Nomadic devices per WG & $0,50 \%$ & 2 & 0 & 1 & 3 & 6 \\
\hline & AVGnumber of Fixed devicesper WG & $0,15 \%$ & 3 & 0 & 2 & 2 & 7 \\
\hline & Total & & 9 & 0 & 5 & 10 & 24 \\
\hline & \multicolumn{6}{|c|}{ Devices per WG: SMEs (School, Hospital, Market, etc) } & \\
\hline & AVGnumber of Mobile devices per WG & $0,55 \%$ & 10 & 0 & 5 & 8 & 23 \\
\hline & AVGnumber of Nomadic devices per WG & $0,15 \%$ & 15 & 0 & 4 & 25 & 44 \\
\hline & AVGnumber of Fixed devices per WG & $0,25 \%$ & 2 & 0 & 5 & 1 & 8 \\
\hline & Total & & 27 & 0 & 14 & 34 & 75 \\
\hline \multirow{4}{*}{ 离 } & \multicolumn{6}{|l|}{ Area per WG: HH } & \\
\hline & AVGArea of each WG $(\mathrm{m} 2)$ & $0,15 \%$ & 200 & 0 & 175 & 220 & \\
\hline & \multicolumn{6}{|l|}{ Area per WG: SMES } & \\
\hline & AVGArea of each WG $(\mathrm{m} 2)$ & $0,50 \%$ & 6000 & 0 & 900 & 1000 & \\
\hline
\end{tabular}

The area is divided into four access networks and each of them has different characteristics. The model divides the wireless grids into two main categories: residential (households) and institutional (schools, hospitals, enterprises, etc.). As said above, we consider that the edge devices are divided into 3 types: Nomadic, mobile and fixed. 
Next table shows the technology parameters required to our model: maximum range of gateway equipment, and the cable type used to link the edge router and GW equipment.

Table 6. Wireless Grids Technology Parameters

\begin{tabular}{|r|c|}
\hline Max. Range of each Gateway $(\mathrm{m})$ & 50,00 \\
\hline Cell width $(\mathrm{m} 2)$ & 5000,00 \\
\hline Cable type & CoaxCable5 \\
\hline
\end{tabular}

The choice of cable is also required to compute the final costs (the data base has several types of cable with the respective cost.

\subsection{Results}

This section presents the final results to support the new requirements of broadband access (fixed and nomadic users) and Wireless grids. Then, we separate the results into these two parts.

Table 7. Broadband Access General Results

\begin{tabular}{|c|c|c|c|c|c|}
\hline & & $\begin{array}{c}\text { Access Network } \\
1\end{array}$ & $\begin{array}{c}\text { Access Network } \\
2\end{array}$ & $\begin{array}{c}\text { Access Network } \\
3 \\
\end{array}$ & $\begin{array}{c}\text { Access Network } \\
4\end{array}$ \\
\hline & \# Fixed Users & 7000 & 0 & 650 & 1150 \\
\hline & \# Nomadic Users & 500 & 0 & 1000 & 0 \\
\hline \multirow{7}{*}{ FTTH } & Payback Period & 12 & 0 & 15 & 26 \\
\hline & NPV & $18.545 .019 €$ & $-€$ & $35.266 €$ & $3.270 .304 €$ \\
\hline & IRR & $6,11 \%$ & $0,00 \%$ & $0,10 \%$ & $-4,46 \%$ \\
\hline & Cost Subc Y1 & $8.812 €$ & $-€$ & $12.997 €$ & $16.620 €$ \\
\hline & \begin{tabular}{|l|} 
Cost Subc Y15 \\
\end{tabular} & $176 €$ & $-€$ & $221 €$ & $256 €$ \\
\hline & CAPEX & $42.056 .667 €$ & $-€$ & $5.494 .978 €$ & $13.136 .344 €$ \\
\hline & OPEX & $8.270 .447 €$ & $-€$ & $809.851 €$ & $1.559 .015 €$ \\
\hline \multirow{7}{*}{ WIMAX } & Payback Period & 14 & 0 & 15 & 15 \\
\hline & NPV & $2.267 .422 €$ & $-€$ & $131.193 €$ & $136.279 €$ \\
\hline & IRR & $1,57 \%$ & $0,00 \%$ & $0,91 \%$ & $0,57 \%$ \\
\hline & Cost Subc Y1 & $5.050 €$ & $-€$ & $5.584 €$ & $5.094 €$ \\
\hline & \begin{tabular}{|l|} 
Cost Subc Y15 \\
\end{tabular} & $482 €$ & $-\epsilon$ & $490 €$ & $471 €$ \\
\hline & CAPEX & $51.478 .055 €$ & $-€$ & $4.809 .506 €$ & $8.763 .517 €$ \\
\hline & OPEX & $15.126 .656 €$ & $-\epsilon$ & $1.399 .396 €$ & $2.525 .258 €$ \\
\hline \multirow{7}{*}{ DSL } & Payback Period & 15 & 0 & 28 & 51 \\
\hline & NPV & $690.024 €$ & $-€$ & $2.373 .143 €$ & $9.427 .161 €$ \\
\hline & IRR & $0,18 \%$ & $0,00 \%$ & $-5,52 \%$ & $-10,60 \%$ \\
\hline & Cost Subc Y1 & $12.860 €$ & $-€$ & $18.761 €$ & $24.487 €$ \\
\hline & Cost Subc Y15 & $203 €$ & $-€ €$ & $262 €$ & $329 €$ \\
\hline & CAPEX & $59.457 .479 €$ & $-€ €$ & $7.839 .295 €$ & $19.126 .195 €$ \\
\hline & OPEX & $8.724 .630 €$ & $-€$ & $873.944 €$ & $1.726 .021 €$ \\
\hline \multirow{7}{*}{$\mathrm{HFC}$} & Payback Period & 13 & 0 & 20 & 30 \\
\hline & NPV & $13.058 .160 €$ & $-€$ & $551.645 €$ & $4.612 .118 €$ \\
\hline & IRR & $3,91 \%$ & $0,00 \%$ & $-1,47 \%$ & $-5,90 \%$ \\
\hline & Cost Subc Y1 & $10.181 €$ & $-€$ & $14.552 €$ & $18.506 €$ \\
\hline & Cost Subc Y15 & $179 €$ & $-€$ & $218 €$ & $266 €$ \\
\hline & CAPEX & $47.412 .355 €$ & $-€$ & $6.063 .773 €$ & $14.424 .870 €$ \\
\hline & OPEX & $8.401 .617 €$ & $-€$ & $827.968 €$ & $1.612 .302 €$ \\
\hline \multirow{7}{*}{ PLC } & Payback Period & 19 & 0 & 28 & 42 \\
\hline & NPV & $5.695 .712 €$ & $€$ & $2.430 .750 €$ & $8.305 .119 €$ \\
\hline & IRR & $-1,40 \%$ & $0,00 \%$ & $-5,49 \%$ & $-9,11 \%$ \\
\hline & Cost Subc Y1 & $14.187 €$ & $-€$ & $19.252 €$ & $23.872 €$ \\
\hline & Cost Subc Y15 & $223 €$ & $-€$ & $257 €$ & $291 €$ \\
\hline & CAPEX & $64.182 .225 €$ & $-€$ & $7.723 .562 €$ & $17.656 .236 €$ \\
\hline & OPEX & $10.385 .620 €$ & $-\epsilon$ & $1.047 .284 €$ & $2.073 .937 €$ \\
\hline
\end{tabular}


Table 7 shows the results for the use of the several technologies to support the static layer (HH and SMEs). Each column corresponds to an access network. The output variables are represented in the lines: Payback period, NPV, IRR, Cost per subscriber in year 1 , and cost per subscriber in year $\mathrm{n}$.

Table 8. Wireless Grids General Results

\begin{tabular}{|c|c|c|c|c|c|c|}
\hline \multicolumn{2}{|c|}{ Total Years: 15} & $\begin{array}{c}\text { Access } \\
\text { Network } 1\end{array}$ & $\begin{array}{c}\text { Access } \\
\text { Network } 2\end{array}$ & $\begin{array}{c}\text { Access } \\
\text { Network } 3\end{array}$ & $\begin{array}{c}\text { Access } \\
\text { Network } 4\end{array}$ & Total Area \\
\hline \multicolumn{7}{|c|}{ Wireless Grids distribution } \\
\hline \multirow{3}{*}{ Year 1} & Total Residential Wireless Grids & 2400 & 0 & 150 & 220 & 2770 \\
\hline & Total Institutional Wireless Grids & 450 & 0 & 75 & 30 & 555 \\
\hline & Total WG (Residential + SME) & 2850 & 0 & 225 & 250 & 3325 \\
\hline \multirow{3}{*}{ Year $n$} & Total Residential Wireless Grids & 3901 & 0 & 244 & 358 & 4502 \\
\hline & Total Institutional Wireless Grids & 731 & 0 & 122 & 49 & 902 \\
\hline & Total WG (Residential + SME) & 4632 & 0 & 366 & 406 & 5404 \\
\hline \multicolumn{7}{|l|}{ Results } \\
\hline \multirow{2}{*}{ Year 1} & CAPEX costs & $541.324 €$ & $-€$ & $32.937 €$ & $35.905 €$ & $610.166 €$ \\
\hline & OPEX costs & $31.577 €$ & $-€$ & $2.030 €$ & $2.234 €$ & $35.840 €$ \\
\hline \multirow{2}{*}{ Year $n$} & CAPEX costs & $29.302 €$ & $-€$ & $1.783 €$ & $1.942 €$ & $33.028 €$ \\
\hline & OPEX costs & $1.707 €$ & $-€$ & $110 €$ & $121 €$ & $1.938 €$ \\
\hline \multirow{2}{*}{ Total } & CAPEX costs & $874.994 €$ & & $53.246 €$ & $58.033 €$ & $986.273 €$ \\
\hline & OPEX costs & $51.033 €$ & $-€$ & $3.281 €$ & $3.611 €$ & $57.924 €$ \\
\hline
\end{tabular}

With the definition of the previous parameters our model calculate the wireless grids CAPEX and OPEX costs for each access network (the scenario is divided into 4 access networks) and for the study period (in this scenario the period is 15 years).

\section{Conclusions}

The evolution of computing and communication networks toward decentralized and distributed systems implies that all the intelligence is on the edge nodes of the networks. Integrating wireless devices with the traditional wired grid infrastructure will allow the access (transfer, processing, etc) to the information that is now scattered across the different devices.

This paper proposes a new architecture to integrate the wireless grids networks with the broadband access networks. The produced results can analyze how the costs vary from region to region, calculating the cost per user, cost per homes passed, payback period, NPV, IRR, end cash balance, CAPEX, OPEX, and so on. The proposal tool performs a detailed comparison of the different broadband access technologies in several scenarios. For each access network, the model chooses the best solution, based in the output results.

\section{References}

[1] Yong-Hyuk, M., Tran, M.T., Chan-Hyun, Y., Heyon-Sun, S., Jung-Yeop, J.: Wireless Grid Middleware Architecture for Providing Reliable Services, pp. 1-6 (2005)

[2] McKnight, L.W., Lehr, W., Howison, J.: Coordinating User and Device Behavior in Wireless Grids. In: Fitzek, F., Katz, M. (eds.) Cognitive Wireless Networks, pp. 679-697. Springer, Netherlands (2007) 
[3] Srinivasan, S.H.: Pervasive wireless grid architecture, pp. 83-88 (2005)

[4] Pereira, J.P., Ferreira, P.: Access Networks for Mobility: A Techno- Economic Model for Broadband Access Technologies. IEEE, Los Alamitos (2009)

[5] Pereira, J.P.: Broadband Access Technologies Evaluation Tool (BATET). Technological and Economic Development of Economy XIII(4), 288-294 (2007)

[6] Sarrocco, C., Ypsilanti, D.: Convergence and Next Generation Networks. In: OECD, CISP (2007)/Final (June 2008)

[7] Vittore, V.: Broadband in High-Growth Economies. In: Lartigue, J.-P. (ed.) Breaking the Barriers - Transformation to the Digital Life, pp. 317-324. Alcatel- Lucent's (2008)

[8] Wellen, J.: High-Speed FTTH Technologies in an Open Access Platform - the European MUSE Project. In: Lin, C. (ed.) Broadband Optical Access Networks and Fiber-to-theHome: Systems Technologies and Deployment Strategies, pp. 139-166. John Wiley \& Sons, Chichester (2006)

[9] McKnight, L.W., Sharif, R.M., Wijngaert, L.: Wireless Grids: Assessing a New Technology from a User Perspective. In: Designing Ubiquitous Information Environments: Socio-Technical Issues and Challenges, pp. 169-181. Springer, Boston (2005)

[10] Benedict, S., Rejitha, R.S., Vasudevan, V.: Threshold Accepting Scheduling Algorithm for Scientific Workflows in Wireless Grids, 1st edn., pp. 686-691 (2008)

[11] McKnight, L.W., Howison, J., Bradner, S.: Guest Editors' Introduction: Wireless GridsDistributed Resource Sharing by Mobile, Nomadic, and Fixed Devices. IEEE Internet Computing 8(4), 24-31 (2004) 